\title{
Que delícia de mulher! - A brasileira na literatura dos oitocentos
}

\author{
Andreia Alves Monteiro DE CASTRO* \\ Universidade do Estado do Rio de Janeiro (UERJ)
}

RESUMO: Na literatura oitocentista, produzida tanto em Portugal como no Brasil, é possível encontrar vários exemplos de associações entre determinadas formas, cheiros, sabores e cores à mulher brasileira, resultando em uma imagem estereotipada e hipererotizada. Em obras como Coração, Cabeça e Estômago (1861), de Camilo Castelo Branco, O Cortiço (1890), de Aluísio de Azevedo e os Mysterios do Porto (1890-1891), de Gervásio Lobato, estas mulheres "mais quentes", "abrasadas pelo escaldante sol dos trópicos", estariam sempre dispostas a realizar todo e qualquer desejo masculino. Tal visão, difundida desde a colonização e profundamente marcada pelo racismo e pelo sexismo, também funciona como um fator de estigmatização, inferiorização e marginalização, uma vez que atribui às brasileiras certas características culturais, comportamentais e físicas que determinariam a sua maior disponibilidade sexual, especialmente, em relação aos europeus, cujos efeitos são sentidos até os dias de hoje.

PALAVRAS-CHAVE: Interculturalidade. Literatura Comparada. Literatura Feminina. Imagem da Mulher.

ABSTRACT: In the nineteenth century literature, produced both in Portugal and Brazil, it is possible to find several examples of associations between deformations, scents, flavors and nuclei of the Brazilian woman, resulting in a stereotyped and hypererotized image. In works like "Heart, Head and Stomach" (1861) by Camilo Castelo Branco, O Cortiço (1890) by Aluísio de Azevedo and the Mysterios do Porto (1890-1891) by Gervásio Lobato, these "hotter" women, scorched by the scorching sun of the tropics, "would always be willing to carry out any and all male desires. Such a view, spread since a colonization and deeply marked by racism and sex, also functions as a factor of stigmatization, inferiorization and marginalization, since it attributes to Brazilians certain cultural, behavioral and physical characteristics that would

\footnotetext{
* Professora Adjunta de Literatura Portuguesa e de Literaturas Africanas de Língua Portuguesa no Instituto de Letras da UERJ. Doutora em Literatura Comparada pela Universidade Estadual do Rio de Janeiro. Membro do Polo de Pesquisa de Relações Luso-Brasileiras do Real Gabinete Português de Leitura. Membro associado ao Centro de Estudos Clássicos da Faculdade de Letras da Universidade de Lisboa. E-mail: andreiaacastro@yahoo.com.br.
} 
determine their greater sexual availability. in relation to the Europeans, whose effects are felt until the present day.

KEYWORDS: Interculturality. Comparative literature. Female Literature. Image of Woman.

Segundo Michele Perrot (2013), no século XIX e em boa parte do XX, não seria adequado à mulher falar abertamente sobre o corpo, nem o seu próprio. A honra feminina era diretamente relacionada ao recato, à submissão e ao silêncio. Contudo, paradoxalmente, o corpo da mulher, desejável e desejoso, estava presente, de maneira quase obsessiva, na pregação religiosa, nos tratados médicos e nas pinturas, nas esculturas, nos poemas e nos romances dos artistas. Praticamente todos os seguimentos sociais falavam dele, mas ele permanecia calado: "As mulheres não falav[am], não $\operatorname{dev}[i a m]$ falar dele. O pudor que encobr[ia] seus membros ou lhes cerra[va] os lábios era a própria marca da feminilidade (PERROT, 2013, p.13).

Reprimido, disciplinado, dissecado, analisado, discutido e representado a exaustão pelos homens, a imagem do corpo feminino também foi socialmente empregada para diversos outros fins, como suporte a propagação de ideias e ideais. Ainda segundo a historiadora francesa, naquele momento, a figuração da mulher servia como veículo de propaganda ideológica e política. As cidades europeias foram tomadas por estátuas em homenagem aos grandes homens coroados por musas evanescentes e por monumentos a mortos heroicos chorados por viúvas e filhas.

A imagem da guerreira Germânia passou a encarnar a unidade da pátria alemã, enquanto Marianne, uma robusta mulher do povo, com o seio descoberto e cingindo o barrete frígio, a representação da Liberdade, da obra de Eugène Delacroix, tornou-se símbolo da República, e não só na França, mas em inúmeros outros países, como Argentina, Brasil e Portugal, quando, estes, proclamaram o mesmo sistema de governo: 
Figura 1 - La Liberté guidant le peuple (1830) - Eugène Delacroix

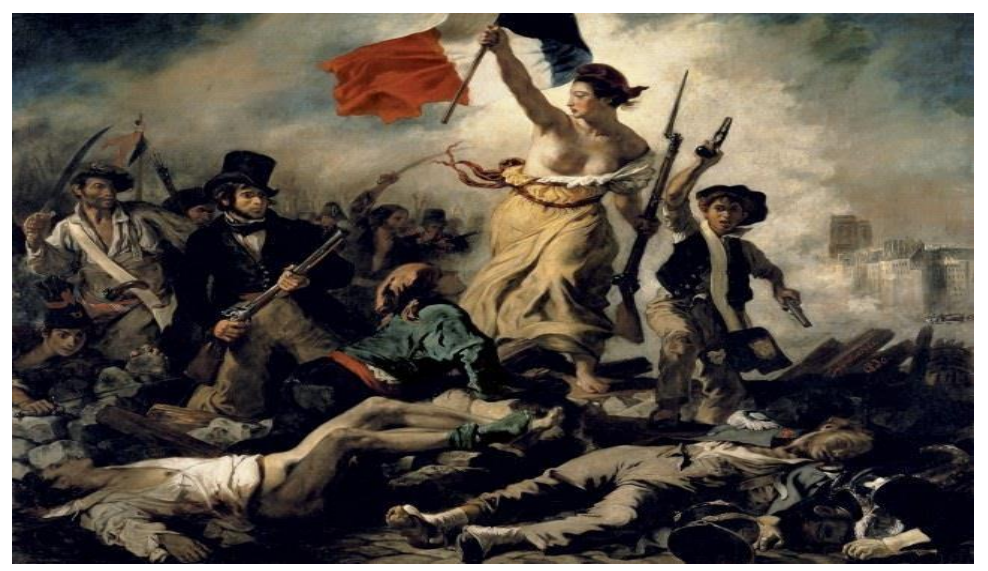

Figura 2 - Ilustração alusiva à Proclamação da República Portuguesa

Litografia colorida, da autoria de Cândido da Silva

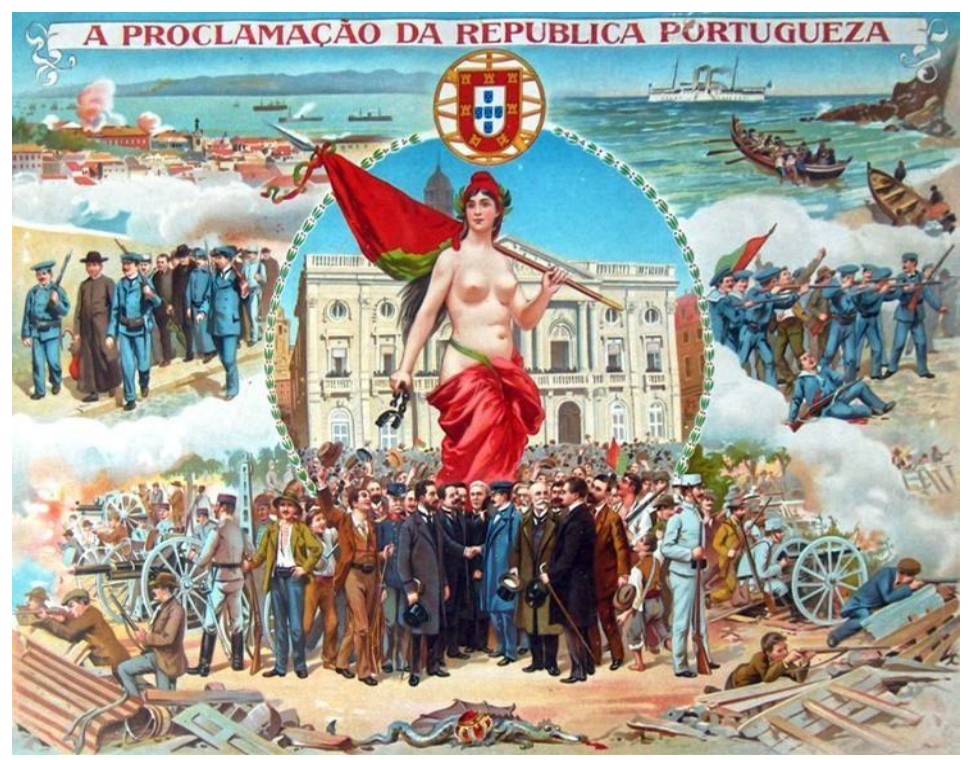


Figura 3 - Glória á Patria!

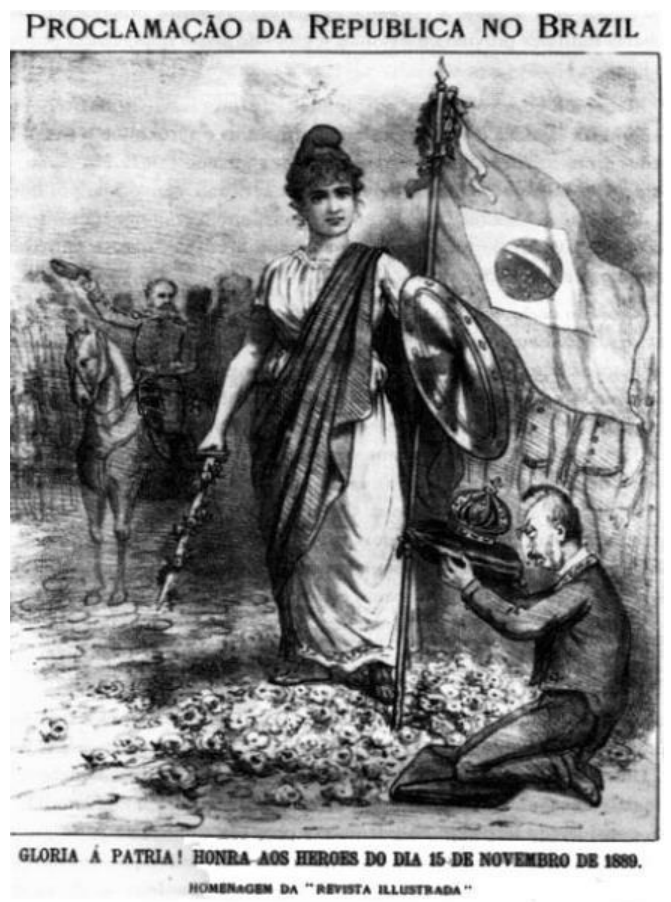

Fonte: Revista Illustrada, 16 nov. 1889.

Para estimular o consumo, já no final dos oitocentos, a publicidade associava a imagem feminina a toda sorte de produtos. Em muitos desses anúncios, é possível perceber a intenção de despertar a atenção e o desejo do leitor através da representação sensual do corpo da mulher tornando igualmente desejável tudo aquilo que com ela se oferecia. O sucesso desta estratégia de venda, como sabemos, foi tamanho, e os corpos femininos nunca mais deixaram de ser padronizados, exibidos e ofertados, simbolicamente ou de fato, mesmo após tantas lutas feministas. 

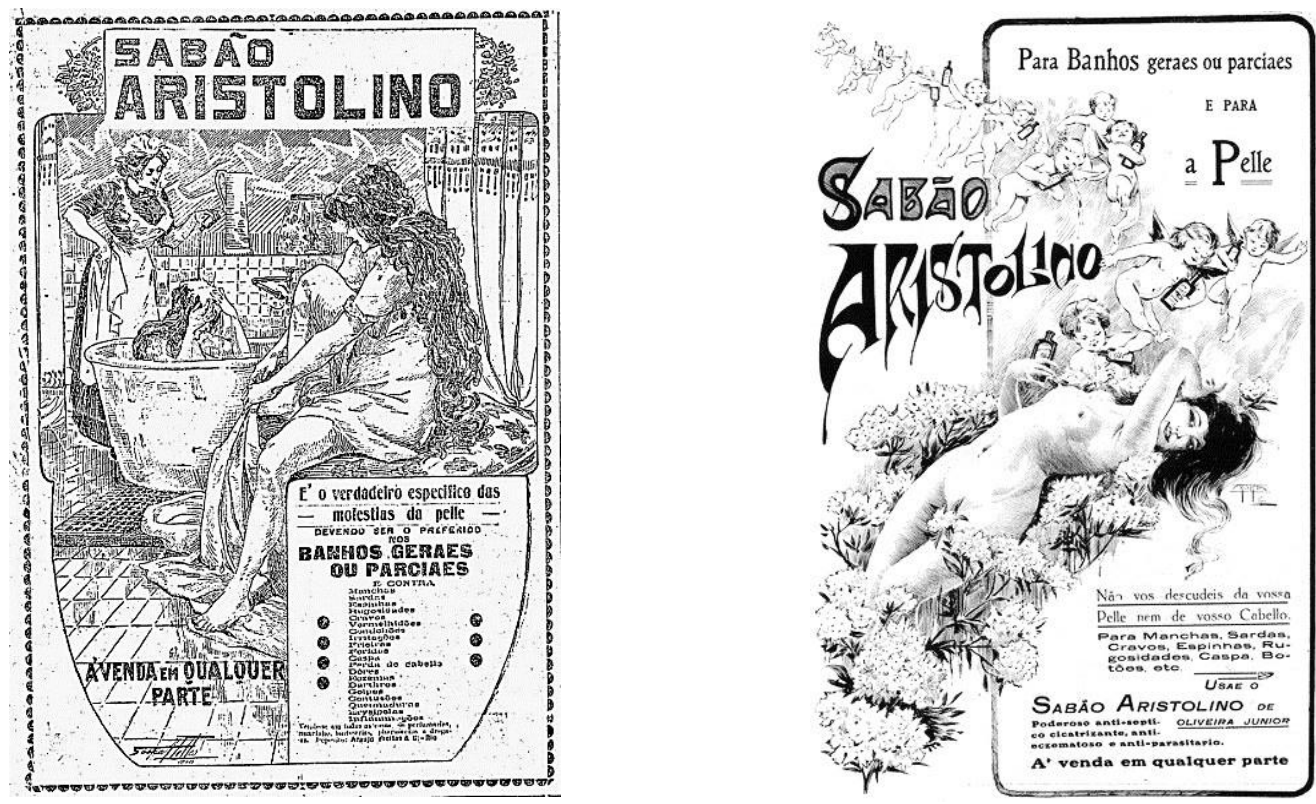

Fonte: O Estado de São Paulo - 1917

$\mathrm{Na}$ esfera da vida privada, o corpo feminino também foi usado como capital simbólico fosse na obtenção ou na manutenção de status social, no caso de mães, esposas e filhas honradas e descentes, ou na afirmação de virilidade e masculinidade, no caso de amantes e das prostitutas, fogosas e sensuais. Nessa equação, a beleza do corpo feminino também sempre teve um grande peso. $\mathrm{O}$ homem que era marido ou amante, ou seja, que possuía uma mulher admirada e, sobretudo, desejada pelos outros, desfrutava de um maior prestígio social.

No Brasil, o longo sistema colonial escravocrata parece ter aprofundado, particularizado ainda mais estas questões. Sob intensa dominação masculina, o corpo da mulher, principalmente as de pele mais escura, estava realmente submetido aos interesses e vontades dos homens dominantes. O corpo das índias e negras era entendido como fonte inesgotável e desimpedida de prazer.

Apregoava-se que essas mulheres, ditas mais quentes, estariam sempre dispostas a realizar todo e qualquer desejo masculino, como sua conformação física e seu temperamento fossem apropriados para tal situação. Como afirma a historiadora Mary Del Priori, a misoginia racista da colônia, as classificava como mulheres fáceis, alvos naturais de investidas sexuais, com que se podia ir direto ao ponto sem causar 
constrangimentos ou melindres. "Degradas e desejadas ao mesmo tempo, as negras seriam o mesmo que prostitutas, no imaginário de nossos colonos: mulheres ,aptas à fornicação ", em troca de algum pagamento" (PRIORI, 2011, p. 46).

Para Quijano (2005), a ideia de raça e das identidades raciais, negros, índios, brancos e mestiços, é algo que surge com a constituição da América. Essas identidades, por sua vez, foram construídas diretamente a partir da inferiorização e desumanização do não branco, deste modo, pessoas negras e indígenas têm, em um primeiro momento, seus traços fenótipos, mentais e culturais desvinculados do que estava sendo arquitetado como racional, ou seja, como uma característica de pessoas civilizadas).

A representação literária destas ardentes "morenas", "pardas" ou "mulatas", trazendo à baila toda a carga significativa subjacente a estes termos, teria contribuído, e muito, para consolidação e para difusão desta visão que acabou servindo de base para a estigmatização, a inferiorização e a marginalização social dessas mulheres.

Para Quijano (2005), a ideia de raça e das identidades raciais, negros, índios, brancos e mestiços, é algo que surge com a constituição da América. Essas identidades, por sua vez, foram construídas diretamente a partir da inferiorização e desumanização do não branco, deste modo, pessoas negras e indígenas têm, em um primeiro momento, seus traços fenótipos, mentais e culturais desvinculados do que estava sendo arquitetado como racional, ou seja, como uma característica de pessoas civilizadas).

Fossem cor de jambo, de canela ou de trigo maduro, a menção às diferentes tonalidades de pele resultantes da miscigenação, com frequência, estava aliada à descrição estereotipada do corpo das brasileiras em geral: seios rijos, cintura fina, quadris largos, glúteos avantajados e pernas bem-torneadas.

Todo este conjunto de atributos físicos, por sua vez, era relacionados a movimentos peculiaridades, apresentados, quase sempre, como gestos e requebros atraentes e lascivos, sobretudo quando cantam e dançam os ritmos de seu povo.

O poeta baiano Gregório de Matos seria um dos primeiros escritores brasileiros a dedicar seus versos às mulheres negras e mestiças. De fato, são centenas, bem mais numerosos do que aqueles destinados a "donzelas" e "senhoras" brancas. Contudo, os poemas do Boca do Inferno eram proeminentemente marcados por uma semântica erótica que revela uma obsessão pelos corpos de pele escura, sempre desfrutáveis aos olhos e ao alcance das mãos masculinas: 


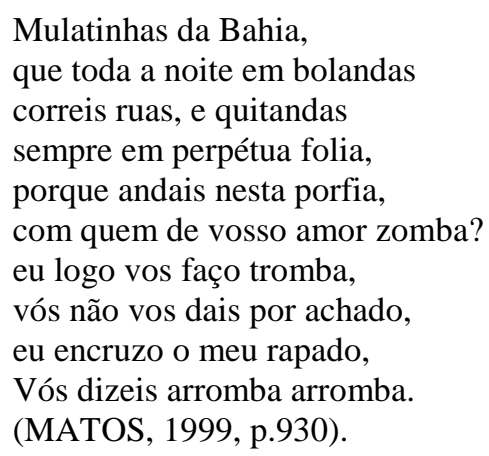

Mas na ficção, bem como na realidade, visão e tato também se separavam dos sentidos no que tange a percepção do corpo feminino pelo homem. Ainda que simplório, este apelo multissensorial e sinestésico já estava presente em um texto publicado por Almeida Garrett, em 1845, nas páginas do periódico A Ilustração.

O escritor português aparentemente influenciado pelo poema épico do frei Santa Rita Durão, tornava pública uma carta remetida por um brasileiro que vivia em Lisboa à sua noiva, a cabocla Moema. O remetente retrata a destinatária como uma sensual morena, tratando-a por epítetos curiosos, como "caju da minha vida", "banana da minha alma" e "maracujá-açu do meu coração".

A despedida que encerra a estranha epístola assinalada pelo exotismo também tem este mesmo cariz: "Limonada refrigerante dos meus ardentes desejos, eu te bebo com o pensamento de cá desta aridez da velha Europa”.

Já o artista plástico Rafael Bordallo Pinheiro, em um relato das suas impressões sobre o Rio de Janeiro e os seus habitantes, publicado na revista brasileira O Mosquito, também não deixou de registrar a sua visão sobre as "explendidas" mulheres brasileiras. De acordo com as vestimentas usadas por cada uma delas, é possível perceber que a mulata foi retratada com um cariz muito mais sensual e exuberante do que as mulheres brancas. 


\section{Figura 5}

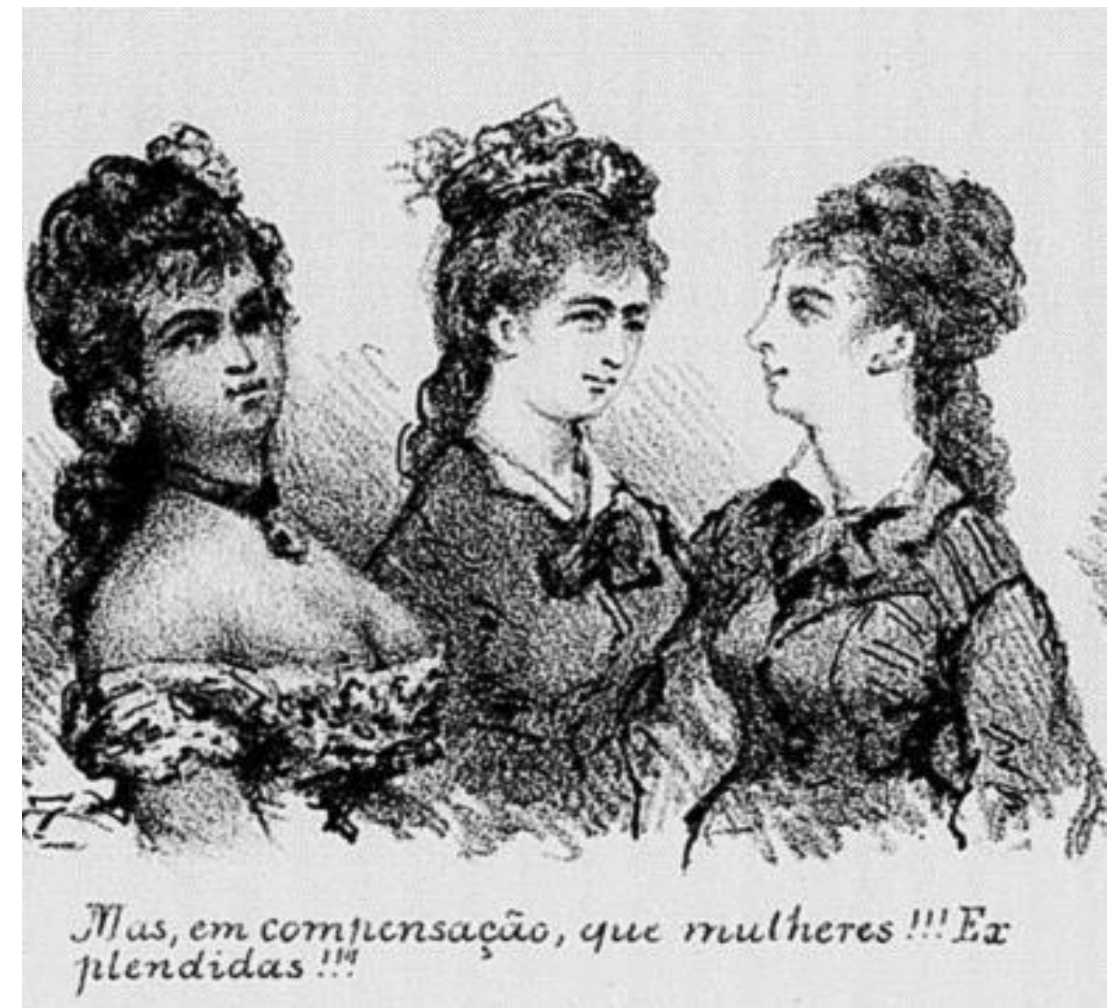

Fonte:O Mosquito, 11 de setembro de 1875 Autor: Rafael Bordalo Pinheiro

Ainda que, como visto, esteja presente em variados gêneros e em diversas épocas, é no romance dos oitocentos que tal "império dos sentidos", vigora. Os corpos das mulheres do Brasil foram amplamente descritos, em narrativas portuguesas e nacionais, a partir de cores fortes, aromas inebriantes e gostos exóticos de flores, frutas, bebidas e temperos, resultando em uma série de adjetivações paradigmáticas na representação das brasileiras na literatura.

Não há como tratar deste tema sem pensar na Iracema de Alencar. A virgem dos lábios de mel, cujo sorriso era mais doce do que o favo da jati e o hálito mais perfumado do que a baunilha dos bosques, também era uma morena astuta e exuberante que, segundo palavras do narrador, dedicava a Martim, branco europeu, amores ardentes. 


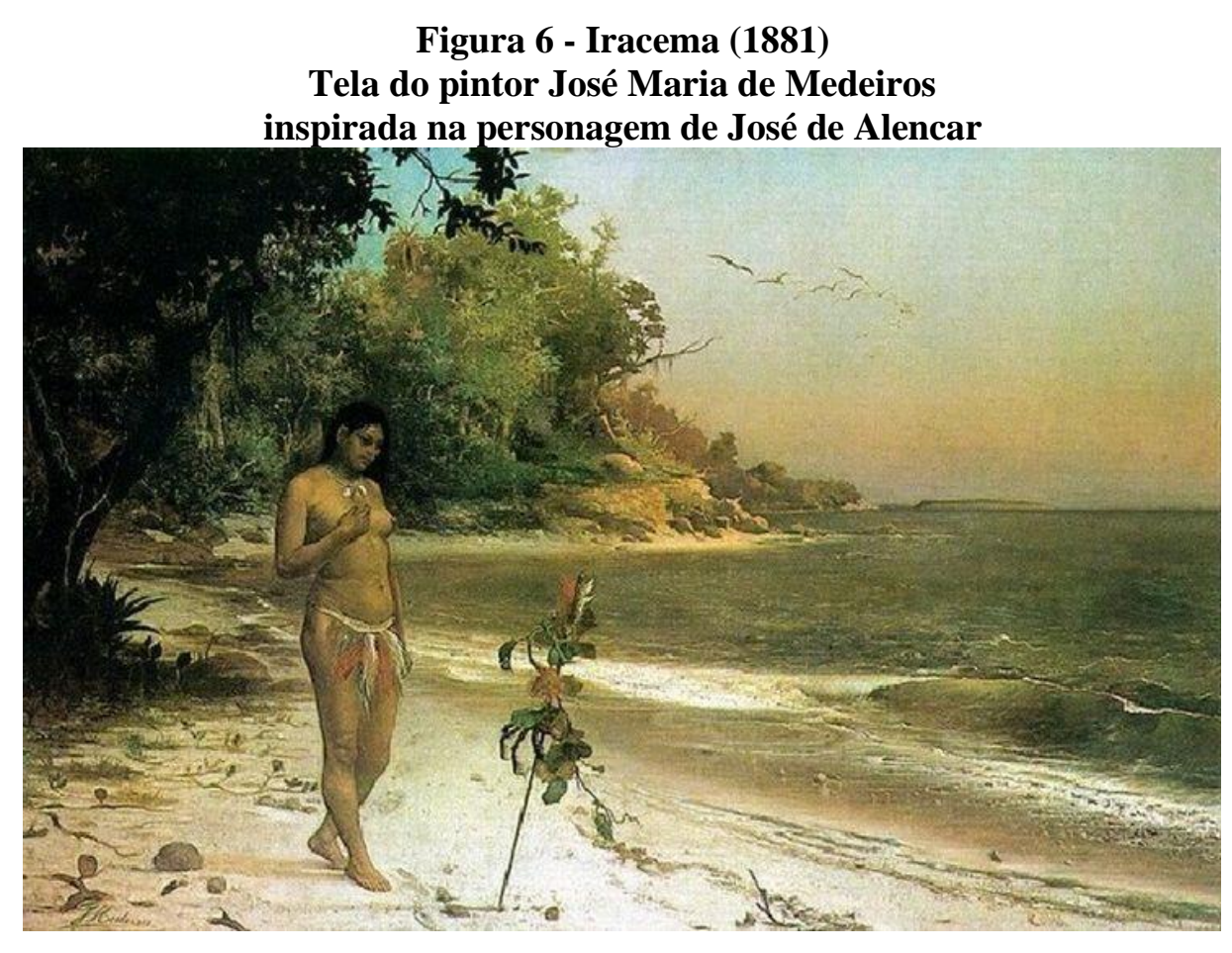

Em aparente contraposição à noção de pureza evocada pela caracterização da personagem e pela repetição do termo virgem atribuído à índia, a menção a amores ardentes é, de fato, um eufemismo para um desejo físico, que, de tão urgente, leva a sacerdotisa a oferecer ao amado o vinho de Tupã, uma bebida com efeitos alucinógenos, com a intenção de vencer a resistência do rapaz ao ato sexual fora dos laços sagrados do matrimônio:

Quando Iracema foi de volta, já o Pajé não estava na cabana; tirou a virgem do seio o vaso que ali trazia oculto sob a carioba de algodão entretecida de penas. Martim lho arrebatou das mãos, e libou as gotas do verde e amargo licor.

Agora podia viver com Iracema, e colher em seus lábios o beijo, que ali viçava entre sorrisos, como o fruto na corola da flor. Podia amá-la, e sugar desse amor o mel e o perfume, sem deixar veneno no seio da virgem.

Quando veio a manhã, ainda achou Iracema ali debruçada, qual borboleta que dormiu no seio do formoso cacto. Em seu lindo semblante acendia o pejo vivos rubores; e como entre os arrebóis da manhã cintila o primeiro raio do sol, em suas faces incendidas rutilava o primeiro sorriso da esposa, aurora de fruído amor. (ALENCAR, 1967, p. 280) 
Portanto, surpreendentemente, no romance, a origem da miscigenação do povo brasileiro seria a violação de um homem branco e não da mulher nativa, retratada por Alencar como uma feiticeira sedutora. Iracema não sobrevive para criar seu filho, fruto de um episódio tão significativo.

A representação da brasileira como uma mulher que é, ao mesmo tempo, sensualíssima, ardilosa e amoral também está presente no romance camiliano Coração, Cabeça e Estômago. Nesta obra, a bela cozinheira que tinha a cor avermelhada e exalava o cheiro de seu apetitoso tempero, evocando, de alguma forma, a Gabriela, que Jorge Amado criaria anos depois, naturalmente, usa todos os seus atributos físicos e intelectuais para seduzir e depois, quando lhe convém, abandonar o protagonista da trama, Silvestre da Silva, que era amante da dona do estabelecimento no qual a morena trabalhava. Tupinyoyo é a figuração de um corpo feminino que não apenas sabe, mas gosta de ter e de dar prazer, sem nenhum embaraço ou questão existencial.

O narrador/personagem emprega expressões como "inferno de devorante lascívia" e "choque da pilha galvânica" para apresentar fisicamente a sua cozinheira, mas, no final do caso amoroso e, coincidentemente, no final do capítulo, a esperteza e a malícia são os qualificadores destacados, como se para o potuguês, mais uma vez, não houvesse escolha a não ser ceder a sedução da brasileira:

Os dias corriam plácidos e felizes para nós, quando D. Martinha tomou uma criada, que era mulata.

Mas que anjo das estuosas zonas onde a pele está calcinada, como devem está-lo as fibras do coração! Que mulata!, que inferno de devorante lascívia ela tinha nos olhos! Que tentação, que doidice me tomou de assalto apenas a vi em roda do meu leito, fazendo a cama! O menor trejeito era uma provocação; o frêmito das saias era um choque da pilha galvânica! (...)

Amei a mulata, com todo o ardor do meu sangue e dos meus vinte anos! (...). Quando a exorava, parece que os nervos me retorciam os músculos; e os músculos se contraíam em espasmos de luciferina delícia! Lembra-me que me ajoelhei a seus pés um dia, beijando-lhe as mãos, que perfumavam o aroma de cebola do refogado. (...)

Perguntai às aves do céu, e às alimárias dos pedregais africanos, como se amam! (...)

O meu amor tinha da ave a meiguice e do tigre a insaciável sofreguidão. (...) 


\begin{abstract}
Ainda lhe não tinha dito que a filha do Brasil era extremamente engraçada, esperta e maliciosa. Aquelas poucas palavras bastam a definila. (CASTELO BRANCO, 1960, p.446)
\end{abstract}

No final do século, estes corpos cheirosos e gostosos eram transcritos como uma ameaça ainda mais gravosa, da qual não se poderia escapar impunimente. Se deixar levar por aquelas sinuosas curvas era tomar o caminho mais curto e certeiro para a degradação moral e até para o crime.

A luxúria atribuída a mulheres, como Rita Baiana, transtornaria o homem branco europeu, ao despertar seus instintos mais animalescos, como acontece com Jerônimo. Para estes homens, aqueles corpos vistos como hiperbolicamente sexuais eram, ao mesmo tempo, "açúcar gostoso" e "veneno", "sapoti mais doce que o mel" e "castanha do caju, que abre feridas com o seu azeite de fogo".

No romance de Aluísio de Azevedo, a mulata também é transfigurada em animais, Rita Baiana era a cobra verde e traiçoeira, a lagarta viscosa, a muriçoca doida cujos movimentos hipnotizam e atraem a vítima, seu corpo zoomorfizado era uma armadilha sem fuga.

Envenenado por um desejo violento e cego, Jerônimo sucumbe, seu corpo fraqueja diante de tamanha volúpia. Rita tentando remediar o português, com presteza e solicitude, lhe serve o seu café temperado com parati. Conforme afirma Leonardo Mendes, o tal elixir de fato simboliza a brasilidade, por ser composta por dois ingredientes tão típicos do país, e de algum modo se remete ao vinho cerimonial servido por Iracema a Martim, pelo menos o efeito foi o mesmo:

\footnotetext{
Como narrativa de refundação da nacionalidade no naturalismo, a história de Rita e Jerônimo retoma a configuração da mulher como o elemento que empurra o homem para a sexualidade com o auxílio de uma bebida mágica. Para Martim, Iracema traz o ,vinho de Tupãee. Rita Baiana traz para Jerônimo (que um pouco antes já bebera ,um trago de paratiec) uma xícara de café - ,a chávena fumegante da perfumosa bebida que tinha sido a mensageira dos seus amores ${ }^{\mathrm{ee}}$. (MENDES, 2000, p. 77).
}

Após provar da mulata, Jerônimo despreza a sua antiga vida. Ele mata Firmo, o amante de Rita, e abandona o emprego, a mulher e a filha, para se entregar de corpo e 
alma àquele relacionamento. Definitivamente, o português honrado deixa de ser quem sempre foi para se tornar um outro alguém muito semelhante aos demais habitantes do cortiço, como se Rita e o lugar fossem de fato extremamente corruptores.

Mas nem todos os escritores finisseculares viam as mulheres como um alimento lascivo e pernicioso. O escritor português, Gervásio Lobato, em seu volumoso folhetim batizado de Os Mistérios do Porto, apresenta e discute inúmeras questões sociais que tornam a rica e bela baronesa mais uma mulher que o mundo despreza, mesmo que, inicialmente, o narrador empregue os mesmos modelos para descrever a morena brasileira, sempre visando excitar a imaginação dos leitores tão acostumados com aquela fonte de prazer:

Deliciosamente morena d'esse moreno quente, sensual, que os poetas cantam e em que o sol ardente do Equador parecia ter posto todo o seu calor lascivo, e que não tem nada de comum com a côr morena peculiar ás meninas rachiticas e chloroticas das nossas cidades insalubres, uma côr doentia, esverdeada, que não passa d'um macilento pouco lavado, que vem da falta de alimentação, da falta de sangue, da falta de ar, e não raro da falta d'agua; com uns olhos enormes, negros, que pareciam ter guardado na retina todos os raios refungentes do sol equatorial, uns cabelos pretos, como plumagem do corvo, fartos , compridos e encrespados(...) uns lábios grossos, amplos, macios, fôfos colchões de beijos, vermelhos como a flôr do cactos, espirrando sangue como se n'esse momento tivessem sido rasgados a bisturi n'aquella carne fresca, para deixár ver o marfim deslumbrante dos seus dentes pequeninos, muito eguaes, muito afiados dentes de whistity, alta, elegante, bem feita, hombros largos, peitos salientes contornados em linhas de primorosa esculptura, ancas amplas que tinham ao andar essa ondulação cadenciada, afrodisíaca, que é o grande segredo de certas raças (LOBATO, 1990, Vol. II, pp.126-127).

Maroca, filha de um desprezado negreiro, se vê forçada a casar com um homem bem mais velho, de má reputação e que quase não conhecia. Nos Mistérios do Porto, o homem é quem tem experiência nas "sciencias de devassidões d"eamor" e exige da esposa, quase uma menina, o cumprimento dos deveres conjugais sem que nenhum jogo de sedução seja encenado. O casamento burguês, retratado através do relacionamento deste par tão assimétrico, se traduz em dissabor para a esposa e rotina insípida para o marido. $\mathrm{O}$ barão tenta se evadir por intermédio da forma mais comum à época, as 
aventuras sexuais com jovens prostitutas, enquanto Marocas acaba por encontrar no adultério a sua saída furtiva. O casal acaba por ter seus segredos revelados e, logicamente, quem sofre o repúdio social é a morena brasileira.

Curiosamente, a crítica contundente à instituição do matrimônio, que ecoa em toda a narrativa, também é apresentada no capítulo intitulado Gallinha e Bacalhau, no qual é narrada uma historieta cômica que contesta a monogamia também através do uso da comida como metáfora para a relação amorosa, terminando com a máxima: até o melhor dos pratos se consumido diariamente enjoa.

Os textos e imagens abordados são apenas alguns exemplos de associações entre determinadas formas, cheiros, sabores e cores à mulher brasileira, que, com frequência, resultavam em uma imagem estereotipada e hipererotizada da mulher brasileira. Tal visão redutora e discriminatória, um senso comum colonial, patriarcal e eurocêntrico inscrito tão profundamente no imaginário coletivo que seus indícios ainda podem ser sentidos na atualidade.

Na literatura, nas artes plásticas, nas notícias e nos anúncios, a mulher brasileira costuma aparecer em destaque. A celebração da beleza e da simpatia das mulheres do Brasil não esconde o preconceito, a ideia de que elas são mais disponíveis ao amor e ao sexo. Ainda mais se forem "morenas", quem nunca ouviu a expressão "mulata tipo exportação"? Muitas das brasileiras, conhecedoras dos temperos e ervas, também são consideradas cozinheiras de mão cheia. Bom café, caipirinha e outras bebidas deliciosas, capazes de despertar o corpo ou de alegrar a alma. Muito samba e rebolado, quadris largos, peitos fartos e muita sensualidade. Mulheres bonitas, sorridentes e sensuais, boa comida e muita água e muito sol. Propaganda excelente para atrair forasteiro presente desde a carta de Caminha e que nunca saiu de moda. Como diz a letra da música de Chico Buarque e Ruy Guerra: "Não existe pecado do lado de baixo do Equador".

No entanto, na literatura do Oitocentos, pratos saborosos e concessões eróticas, que antes eram apenas aproximados, agora se misturam, se interpenetram. A mulata é dita imbatível na cozinha e na cama. Cozinhar, amar, duas atividades complementares, se tornam sinônimas e são exploradas em toda sua complexidade e ambiguidade nos textos verbais ou puramente iconográficos. A "mulher-fruto", a "mulher-refeição" e, finalmente, a "mulher-presa" remetem aos estudos de Affonso Romano de Sant "Anna, $^{\text {ee }}$ 
que trabalha o tema na perspectiva do canibalismo amoroso, principalmente no que concerne às relações entre o homem branco e a mulher negra ou mulata: "caçá- la/comêla/devorá-la constituem aspectos reveladores de um esquema representativo das relações eróticas inter-raciais que os escritores brasileiros desenvolveram por mimetismo de neocolonizado" (LAROCHE, 1989, p. 16).

Não sendo um fenômeno novo, obviamente, mas resultado de anos de dominação física e simbólica de um sociedade colonial e pós-colonial, a inovação foi o discurso, mas de êxito tão avassalador, que as temidas índias antropófagas brasileiras, convivas lascivas e ferozes, viraram prato principal nos textos da formulação da nacionalidade brasileira feitos pelos nossos românticos. Depois das índias românticas, as mulatas sestrosas naturalistas, e depois destas, só restavam as brancas. Nem elas ficaram de fora. Prova disto é a cantora Carmen Miranda. A pequena notável com suas vestes de baiana estilizada e o arranjo de frutas tropicais, não deixou por menos, e a portuguesa ficou eternizada internacionalmente como uma delícia de mulher... brasileira. Sem falar nas mulheres-fruta do Funk carioca do século XXI. Som de preto e favelado, mas a representação feminina continuou a mesma do branco europeu.

Em 2014, o governo solicitou que a marca Adidas, patrocinadora oficial da Copa do Mundo, retirasse do mercado camisetas relacionadas ao evento e vendidas no exterior, porque tinha um claro apelo sexual. Em uma delas, havia um coração no formato similar a um corpo feminino, trajando um fio dental e trazendo a expressão "I love Brazil". A outra o slogan dizia: "Lookin' to score", expressão que pode ser entendida como "buscando gols" ou "querendo faturar", associada a imagem de uma mulata ao lado do Pão de Açúcar.

Figura 7
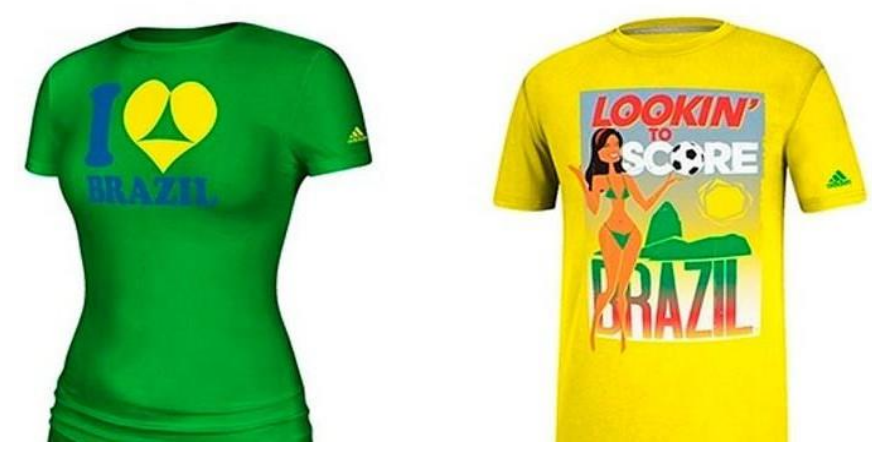

Fonte: http://globoesporte.globo.com/futebol/copa-do-mundo/noticia/2014/02/adidaslanca-camisas-da-copa-com-conotacao-sexual-e-governo-repudia.html 


\section{REFERÊNCIAS:}

ALENCAR, José. Iracema. Rio de Janeiro: José Olympio, 1967.

AZEVEDO, Aluísio. O cortiço. Rio de Janeiro: Ática, 2009.

CASTELO BRANCO, Camilo. Coração, cabeça e estômago, In: Obras seletas. Rio de Janeiro: Aguilar, 1960.

GARRETT, Almeida. O brasileiro em Lisboa. A Ilustração, Lisboa, v. 1, n. 4, 1845. p. 53-54.

LAROCHE, Maximilien. La découverte de l'Amérique par les Américains. Québec: GRELCA, 1989.

LOBATO, Gervásio. Os Mistérios do Porto. Porto: Empreza Litteraria e Typographica, 1890-1891.

MENDES, Leonardo. O retrato do Imperador: negociação, sexualidade e romance naturalista no Brasil. Porto Alegre: EDIPUCRS, 2000.

PRIORE, Mary del. Sexualidade e erotismo na história do Brasil. São Paulo: Editora Planeta do Brasil, 2011.

PERROT, Michele. Os silêncios e o corpo da mulher In: O corpo feminino em debate. Org.Maria Izilda Santos de Matos, Rachel Soihet. São Paulo: Editora UNESP 2003. QUIJANO, Aníbal. Colonialidade do poder, eurocentrismo e América Latina. In: LANDER, Edgardo (Org.). A colonialidade do saber: eurocentrismo e ciências sociais. Buenos Aires: Conselho Latino-americano de Ciências Sociais - CLACSO, 2005. p. 107-130.

RAMOS, Alberto Guerreiro. Introdução crítica à sociologia brasileira. Rio de Janeiro: Editora UFRJ, 1995.

SANT'ANNA, Affonso Romano de. O canibalismo amoroso. São Paulo: Brasiliense, 1984. 